\title{
Research on Prediction and Engineering Application of Deep Mining Rock burst in Metal Mine
}

\author{
Hongsen Luo ${ }^{1,2, a}$, LI Chao ${ }^{1, b}$ \\ ${ }^{1}$ Faculty of Technology, Sichuan Normal University, Chengdu 610101, China \\ ${ }^{2}$ Sichuan Guangtai Construction Engineering Co. Ltd, Chengdu 610100, China \\ aluohongsen@163.com, ${ }^{\mathrm{b}} 852415162 @ q q . c o m$
}

Keywords: Metal mine; Rock burst; Prediction.

\begin{abstract}
Rock burst in metal mine has been the main problem which interferes with mining working at depth. And its corresponding formation mechanism is so complicated that the rock burst theory cannot come up with the practical engineering research. So it is necessary to establish the corresponding geological structure stress model of the mining area studied, analyze its mechanism and put forward the prediction of rock burst location in mining area. Based on the corresponding geological structure stress data of Tongshan mine in Sichuan, this paper establishes the three-dimensional finite element modeling with numerical simulation, in order to calculate, analyze and predict the structure stress and the location where the rock burst may occur within the range of 3 kilometers in this mine.
\end{abstract}

\section{Introduction}

Rock burst is a natural disaster which loses dynamic balance. Due to the great geostress, the excavation load leads to the differentiation of stress and the sudden release of the elastic energy in rock mass. Directly affects the working efficiency of the metal mining enterprises, increases its economic costs, and even leads to safety accidents. How to forecast rock burst in mining process effectively, has become one of the challenges faced by the underground project worldwide. Rock burst prediction is mainly based on the forming mechanism of rock burst from the qualitative or quantitative analysis of the rock burst orientation, and the research methods mainly include the theory analysis and the field measurement method. Currently, a completed and mature set of theory and method has not yet formed either at home or abroad. With the development of computer science and technology, the applications of artificial intelligence, expert system and numerical analysis have become an important direction in rock burst prediction ${ }^{[1]}$. This paper studies the rock burst of mining at depth in Tongshan mine, Sichuan. The main method is the application of ANSYS finite element analysis simulation tools, setting up the three-dimensional geostress model, analyzing the region stress and local mining roadway by finite element, combined with the corresponding numerical analysis structure, studying its mining energy distribution law of surrounding rocks. Whether the burst would come out or not and the corresponding damage degree are predicted in terms of the related criteria of rock burst. Through this method, the rock burst position and destruction area can be determined in the practical engineering process of mining at depth, providing the corresponding regional stress field distribution and the corresponding basis for safety production, which guarantees the safety of staff underground as a result.

\section{Analysis of tectonic stress environment of Tongshan mine in Sichuan}

After 30 years of mining in Tongshan mine, the main mining site is deeper than $500 \mathrm{~m}$, and the corresponding development engineering has reached the depth of $1100 \mathrm{~m}$. According to the relevant engineering experience, the exploit depth has been near the critical point of rock burst. Its main feature is the tectonic stress of mining area is very high, and the shallow horizontal stress on the surface is greater than gravity stress. Because of the influence of the corresponding mining work, 
stress concentration area has emerged in this region, large energy is gathered inside the rock mass, and the condition of rock burst has developed. On the basis of geological and stress data until now, the residual tectonic stress on horizontal direction is huge, and two horizontal stress of its weight, have separately become a maximum and minimum principal stress, that is: $\sigma_{2}{ }^{\prime}=\sigma_{2}{ }^{\prime}=(0.25 \sim 0.40) \sigma_{z}$, gravity maximum vertical stress becomes a principal stress stress field under the condition of gravity: $\sigma_{2}=\sigma_{z}$. The east side of Tongshan mine: $\sigma_{1}=(2.17 \sim 3.33) \gamma h, \sigma_{3}=(0.33 \sim 0.59) \gamma h$; The west side of Tongshan mine: $\sigma_{1}=(1.27 \sim 2.16) \gamma h, \sigma_{3}=(0.27 \sim 0.59) \gamma h$. The planar projection of the main ore body of Tongshan mine is shown in figure 1.

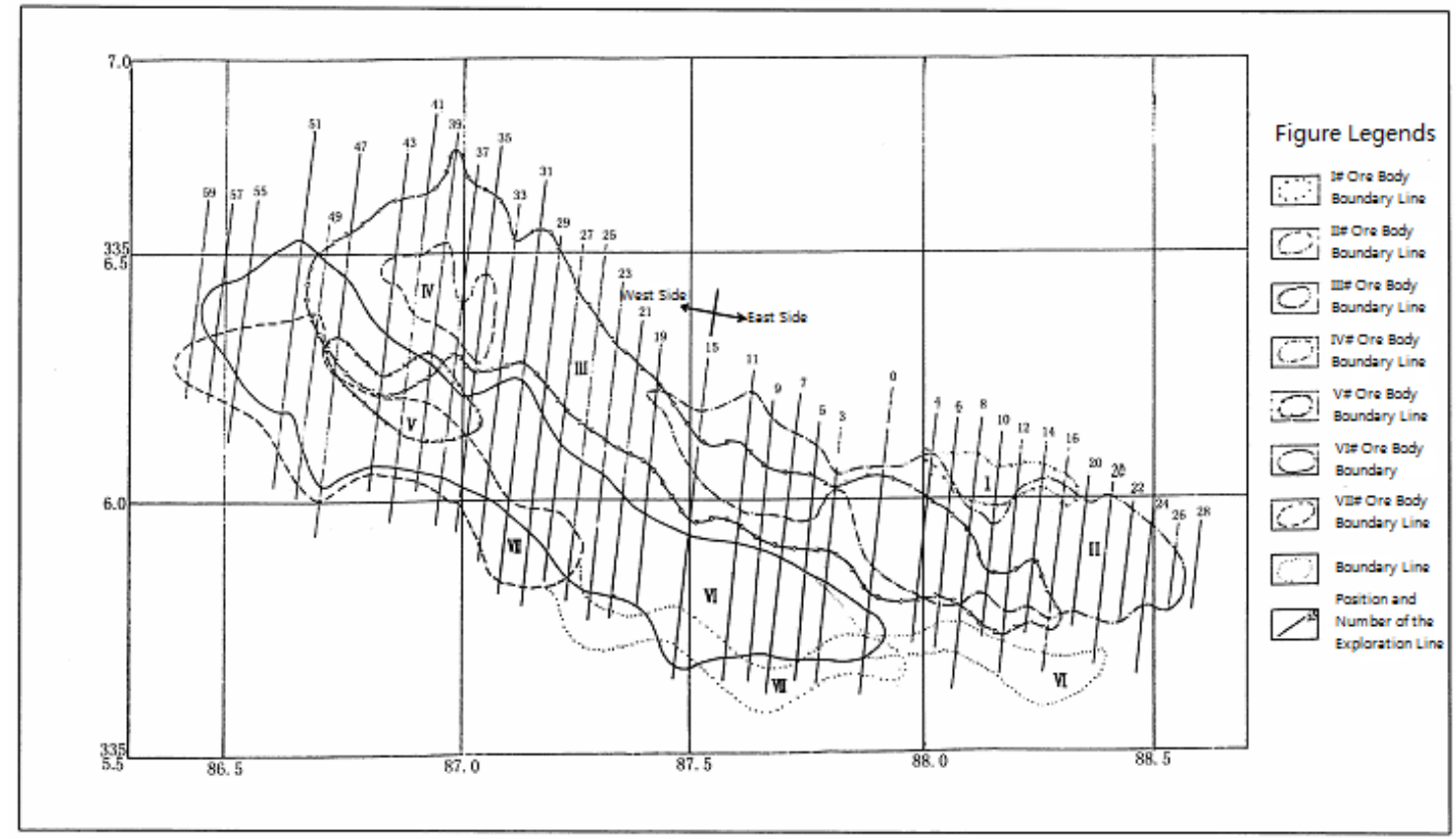

Fig.1 Planar Projection of Ore Body in Tongshan Mine

\section{Numerical modeling for Tongshan mine}

Numerical modeling of finite element. In the process of deep mining, misestimating the stress of the surrounding rock mass will make the rock burst suddenly, impacting the production progress and the safety of the staff; Under estimating the strength of the surrounding rock mass will make the mining and project design too conservative, increase the mining cost, which leads to waste the corresponding financial and material resources. Because the analysis of the mine stress field is a complex result combined with multiple factors, the three-dimensional finite element model is chosen for analysis and calculation according to the actual situation of engineering in Tongshan mine area. Setting the measured geostress information as the calculation reference points of the finite element numerical simulation method, makes the corresponding structure closer to the actual situation.

The establishment of finite element three-dimensional modeling

The 1:5000 prospecting line section map, 1:5000 present situation map of the mining environment and 1:1000 geographical cross-section diagram between $-430 \mathrm{~m}$ and $-640 \mathrm{~m}$ level are collected as the main geological data of Tongshan mine. Taking computer processing speed and accuracy requirements into account, a total range of 3 kilometers is chosen from the mine, east to the production department, and west to Xi Wang Chong. Mining depth selection is mainly based on the following two aspects, one is to assume the coordination of the model size, therefore, $-1000 \mathrm{~m}$ is selected as the altitude; The other is for the reference of related documents and to calculate the structure, only $-430 \mathrm{~m} \sim 800 \mathrm{~m}$ need to be considered. Bottomless sublevel caving mining is applying in Tongshan mine. In the modeling process, due to the influence of strata subsidence zone, $-428 \mathrm{~m} \sim 150 \mathrm{~m}$ is approximately set as the subsidence zone, whose upper angle of $-430 \mathrm{~m}$ level is $55^{\circ}$ and lower angle $65^{\circ}$. The finite element model of Tongshan mining area is shown in figure 2 . 


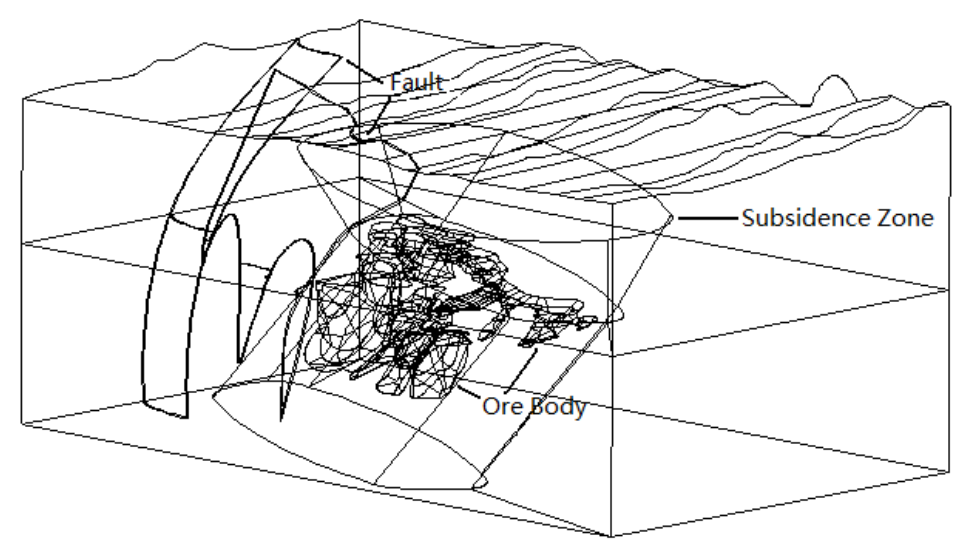

Fig.2 Finite Element Modeling of Tongshan Mine

Yield criterion. Mohr-Coulomb yield surface has some defects in practical engineering application. When the stress is located in or near the corners, it is so hard to determine the outer normal derivative of yield function along the surface that the numerical calculation for viscoplastic strain rate cannot be accurate. Drucker-Praher modified it based on Mohr-Coulomb and Mises criteria:

$$
f=\alpha I_{1}+\sqrt{J_{2}}-K=0
$$

In the above formula: $I_{1}$ and $J_{2}$ are the first constant of stress tensor and the second constant of stress deviator respectively. $\alpha$ and $K$ are internal friction angle of rock and experimental constant of cohesive force respectively:

$$
\begin{aligned}
& \alpha=\frac{2 \sin \varphi}{\sqrt{3}(3-\sin \varphi)} \\
& K=\frac{6 \cos \varphi}{\sqrt{3}(3-\sin \varphi)}
\end{aligned}
$$

Finite element modeling of stress in mining area. The distribution nephograms of vertical maximum principal stress $\sigma_{1}$ both in mining area and ore body are shown in figure 3 and figure 4 . After mining at $-430 \mathrm{~m}$ level, large tensile stress exists at $-500 \mathrm{~m}$ level, the maximum stress is 14.5 $\mathrm{MPa}$. The main reason is that influenced by the upper mining and engineering, large mined-out areas or loose covering layers appear and the concentrated underground stress comes out. With the mining depth increasing, the tensile stress changes into compressive stress, and its quantity increases. The three-dimensional simulation results show that there exists a high geostress field in Tongshan mining area, whose depth is $1000 \mathrm{~m}$ and the maximum value $44 \mathrm{MPa}$.

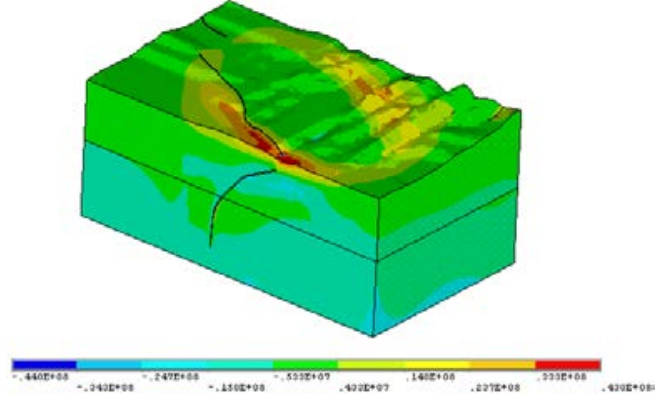

Fig.3 Vertical maximum stress nephogram of the mining area

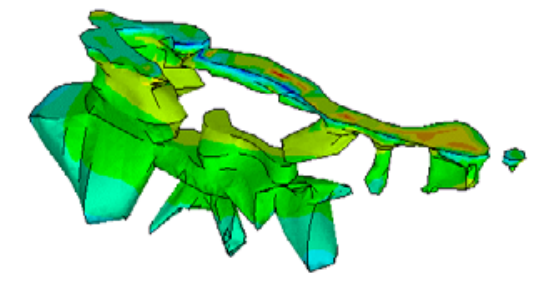

Fig.4 Vertical maximum stress nephogram of the ore body

\section{Evaluation of rock burst prediction}

Sufficient and necessary conditions of rock burst in mines are as follows. Firstly, the rock itself can store a lot of elastic strain energy; secondly, there exists the related environment to produce high stress and accumulate energy. Based on the finite element calculation and analysis, the distribution 
features and quantity of the elastic strain energy in surrounding rocks after deep mining can be obtained, the calculation formula is:

$$
W_{e}=\left(\sigma_{1} \omega_{1}+\sigma_{2} \omega_{2}+\sigma_{3} \omega_{3}\right) / 2
$$

In the above formula: $\sigma_{1}, \varepsilon_{1}, \sigma_{2}, \varepsilon_{2}, \sigma_{3}, \varepsilon_{3}$ are the principal stress and strain of rock unit respectively. Related researches at home and abroad as well as the field monitoring show that, if the internal elastic energy of rock mass reaches or exceeds $1.0 \times 10^{5} \mathrm{~J} \cdot \mathrm{m}^{3}$, corresponding impact ground pressure and rock burst will happen. Figure 5 is the elastic strain energy distribution nephogram of mining area at $-430 \mathrm{~m}$ level, and the related calculation results show that the rock mass has high horizontal elastic energy at $-500 \mathrm{~m}$, as shown in figure 6 . When mining below $-500 \mathrm{~m}$, there will be the phenomenon of rock burst and ejection.

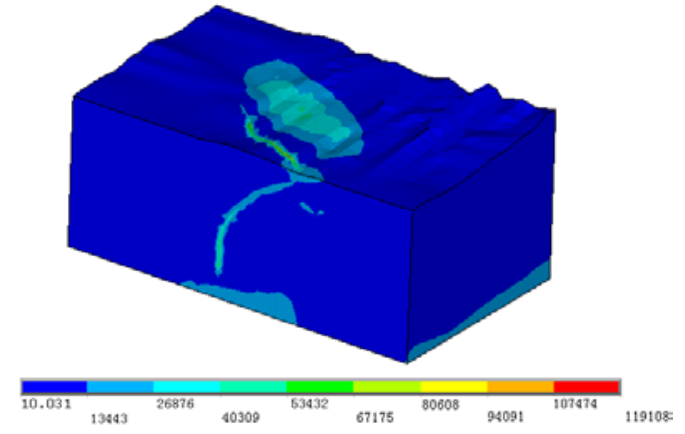

Fig.5 Variation nephogram of elastic energy in $-430 \mathrm{~m}$ mine area

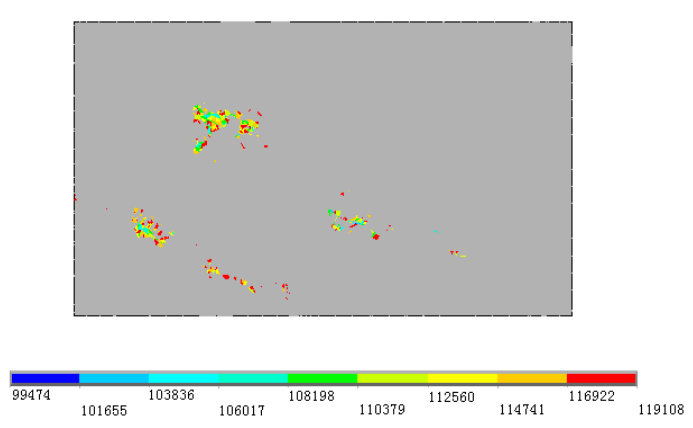

Fig.6 Variation nephogram of elastic energy in $-500 \mathrm{~m}$ mine area

\section{Conclusion}

Aiming at the structure stress circumstances of Tongshan mining area, applying numerical simulation of finite element method, establishing the three-dimensional finite element model of Tongshan mine, setting the corresponding yield criterion, the experimental results show that the maximum tensile stress is $44 \mathrm{MPa}$ at $-1000 \mathrm{~m}$ in Tongshan mine. On this basis, this paper studies the location where the rock burst may occur in the mine area. Through the corresponding judging criteria of rock burst, continual mining under $-500 \mathrm{~m}$ in the mine area will lead to rock burst or rock ejection for sure.

\section{Acknowledgments}

The corresponding author of this paper is LI Chao. The paper is supported by Education Office of Sichuan Province (No.12ZB115).

\section{References}

[1] Guo Li. The model to dynamically predict rock burst proneness of hard rock at depth and its application, D. Central South University, Changsha. (2009) 1-2.

[2] Gu De-sheng, Li Xi-bin. Science problems and research state of deep mining in metal and nonferrous mines, C. The fifth academic annual conference papers of China Nonferrous Metal Institute. Mining research and development magazine, Changsha. (2010) 1-4.

[3] He Man-chao, Xie He-ping, Peng Su-ping. Study on Rock Mechanics in Deep Mining Engineering, J. Chinese Journal of Rock Mechanics and Engineering. 24 (2009) 2803-2813.

[4] Miu Xiao-jun, Wu Ji-min, Li Jing-bo. Causes of rock burst in circular chambers and its geological disaster analysis, J. Journal of Hohai University (Natural Sciences). 30 (2011) 37-40.

[5] Zhu Qi-hu, Lu Wen-bo, Sun Jin-shan. Discussion on mechanism of rock burst and stress state based on energy principles, J. Engineering Journal of Wuhan University. 40 (2007) 84-87. 